\title{
Laser-induced incandescence
}

\author{
Stefan Will ${ }^{1}$ Klaus Peter Geigle ${ }^{2}$
}

Received: 7 May 2020 / Accepted: 7 May 2020

(c) The Author(s) 2020

Laser-induced incandescence (LII) has developed as a versatile technique for particle measurements in combustion, atmospheric, aerosol and nanoparticle science. Since early developments of the technique, laser-induced incandescence has attracted lots of research teams to apply the technique to a wide variety of different test cases. The realization of the technique has spread into different branches, namely imaging LII and time-resolved LII. The variety is also reflected by studies of different nanomaterials or physical conditions under which those particles are characterized. While application has brought insight into the respective processes otherwise inaccessible, researchers have also identified open questions and challenges. These questions arise even more as the field of experimental approaches and application cases is very wide and covers low or high pressure, ambient or high temperatures, high or low particle concentrations, or various soot maturities affecting the LII response-all of these factors demanding for different experimental setup and interpretation approaches.

After five previous special issues of Applied Physics B devoted to this optical diagnostic technique, also this topical collection vividly demonstrates that there are still many important and interesting developments going on in the field of LII science related both to a better fundamental understanding of LII and to its extended application, often in combination with other measurement techniques.

Stefan Will

stefan.will@fau.de

$\triangle$ Klaus Peter Geigle

KlausPeter.Geigle@dlr.de

1 Lehrstuhl für Technische Thermodynamik (LTT) and Erlangen Graduate School in Advanced Optical Technologies (SAOT), Friedrich-Alexander-Universität Erlangen-Nürnberg (FAU), Am Weichselgarten 8, 91058 Erlangen, Germany

2 Institute of Combustion Technology, German Aerospace Center (DLR), Pfaffenwaldring 38-40, 70569 Stuttgart, Germany
This topical collection comprises 15 articles underlining both the complexity and versatility of this technique. While it is very simple to generate an LII signal, "just shoot a strong pulsed laser into a sooting flame and watch", there are many aspects to be considered for a proper execution and data evaluation. In this sense, there is work dealing with basic, yet highly important aspects such as proper calibration, soot maturity issues, and the handling of beam steering; other papers deeply investigate long standing questions, e.g., as to what extent particle size distributions may be obtained from LII.

The combined use with other methods may significantly enhance the capabilities of LII. In this context and in this collection, elastic light scattering, laser-induced fluorescence, cavity ring-down extinction and photoacoustic techniques show how complementary information may be favorably obtained. Applications deal with such diverse objects as an aero-engine combustor and a wood pellet fueled boiler; while, other articles address the use of the technique for investigating metallic or oxidic nanoparticles or carbon nanotubes.

In summary, we believe that this topical issues do not only provide a good insight to every scientist interested in the field of optical particle diagnostics, but also give "LII specialists" plenty of new material useful for their work in advancing laser-induced incandescence. However, even this 6th topical collection does not claim to provide answers to all open questions related to LII and we expect further ongoing research on persistent challenges associated with this technique.

We would like to express our gratitude to the Editorin-Chief Dieter Meschede for his continuous support and advice, and to the editorial office for their help in the production of this topical collection.

Acknowledgments Open Access funding provided by Projekt DEAL.

Open Access This article is licensed under a Creative Commons Attribution 4.0 International License, which permits use, sharing, adaptation, distribution and reproduction in any medium or format, as long 
as you give appropriate credit to the original author(s) and the source, provide a link to the Creative Commons licence, and indicate if changes were made. The images or other third party material in this article are included in the article's Creative Commons licence, unless indicated otherwise in a credit line to the material. If material is not included in the article's Creative Commons licence and your intended use is not permitted by statutory regulation or exceeds the permitted use, you will need to obtain permission directly from the copyright holder. To view a copy of this licence, visit http://creativecommons.org/licenses/by/4.0/.
Publisher's Note Springer Nature remains neutral with regard to jurisdictional claims in published maps and institutional affiliations. 